\title{
Application of design of experiment on electrophoretic deposition of glass-ceramic coating materials from an aqueous bath
}

\author{
SOMESWAR DATTA \\ Central Glass and Ceramic Research Institute, Calcutta 700 032, India
}

MS received 2 November 1999; revised 25 January 2000

\begin{abstract}
A process for application of abrasion- or corrosion-resistant glass-ceramic coating materials on metal substrate by electrophoretic deposition technique in an aqueous medium has been described. The effects of various process parameters, e.g. coating material concentration, time of deposition, applied current, $\mathrm{pH}$ of the suspension and concentration of the polymeric dispersant on the deposition efficiency have been studied. The process has been studied using a $2^{3}$-factorial design technique of three independent variables; i.e. coating material concentration, applied current, and the time taken to achieve the best combination. The regression equation obtained explains the experimental results satisfactorily.
\end{abstract}

Keywords. Coating; electrophoretic deposition; glass-ceramic; design of experiment.

\section{Introduction}

Glassy or glass-ceramic-based oxide coatings are a vital technology for numerous hi-tech applications. Abrasionresistant glass-ceramic coatings on mild steel, applied by conventional vitreous enamelling process (Maskall and White 1986; Datta 1995), increases the service life of machine tool slides (Sen et al 1989). However, conventional spraying or dipping process of application of such coatings can not maintain the critical dimensional tolerance required for precision engineering components.

Electrophoretic deposition technique (EPD) was established to synthesize lamellar, fibre-reinforced and functionally graded composites (Nicholson et al 1996; Sarkar et al 1997a, b). The method was also used for deposition of ceramic materials like $\mathrm{NiO}, \mathrm{Al}_{2} \mathrm{O}_{3}, \mathrm{TiO}_{2}$, $\mathrm{SiC}$, etc from aqueous and nonaqueous baths and is a cost-effective and efficient process to obtain uniform deposit thickness (Hoffman and Rickmann 1978; Das et al 1979; Sinha Mahapatra and Dhananjayan 1981; Ramasamy et al 1983; Maiti et al 1989).

The process is completely controllable via coating material concentration in the bath (CMC), deposition current, and time (Sarkar and Nicholson 1996). However, the technique has not yet been explored for deposition of prepared glassy or glass-ceramic coating materials on metal parts from aqueous bath.

A detailed study made on electrophoretic deposition of various suitable glass-ceramic coating materials, from an aqueous bath, on mild steel and stainless steel substrate has been reported in this paper. The investigation has been mainly confined to identify suitable conditions to achieve maximum deposition efficiency (rate of deposi- tion) for complete coverage of the metal substrate with an uniform coat thickness ranging from $50-100 \mu$. The rate of deposition of coating materials has been studied using a $2^{3}$-factorial design technique of three independent variables; i.e. coating material concentration in the bath (1.0-5.0 wt\%), current (50-150) in milli amperes, and time (1-5) in min taken to achieve the best combination. The range of independent experimental parameters has been selected on the basis of initial experimental observations.

\section{Experimental}

The preparation, properties and characterization of glassceramic coating compositions used in this work have been reported elsewhere (Biswas et al 1986; Datta 1998). The coating materials were prepared and tested accordingly prior to use in subsequent experiments. The schematic diagram of electrode arrangement in the electrophoretic cell, which was used for coating small plate/coupon, has been reported elsewhere (Maiti et al 1989). A $500 \mathrm{ml}$ glass or polythene container was used as the deposition cell. A regulated D.C. power supply source of capacity $200 \mathrm{~mA}$ and $1000 \mathrm{~V}$ was used to supply the necessary electric power. The built-in resistances in the power unit were controlled, in order to obtain constant current or constant voltage.

The $\mathrm{pH}$ of the suspension was determined by a $\mathrm{pH}$ meter (ELCO make), using a standardized glass electrode. The polyacrylic acid used as dispersant was supplied by M/s Rup Rasayan Industries Pvt. Ltd., Bombay, (mol. wt $\left.3 \cdot 5-4 \cdot 0 \times 10^{6}\right)$. Triethylamine and other chemicals used were of laboratory reagent grade. 
The zeta potential of the suspension was measured at various $\mathrm{pH}$ levels, using a zetameter (Matco) at room temperature. The metal substrate was cleaned by sand blasting, but mild steel plates were further etched in a $8 \%$ phosphoric acid bath $\left(80^{\circ} \mathrm{C}, 5-6 \mathrm{~min}\right)$ and rinsed thoroughly in running tap water followed by distilled water, and dried before deposition. The plates were used immediately to avoid further surface oxidation. The predetermined amount of coating material (as a -300 -mesh fine powder) and polymer (dispersant) was milled for $2-3 \mathrm{~h}$ in a polythene jar with alumina balls, and double-distilled water to obtain a thick slurry. The milled suspension was allowed to stand for $1 \mathrm{~h}$ (for settling down of any coarser particles), and then decanted carefully in the electrophoretic cell. The electrode set-up was immersed in it and connected to the power supply. After EPD, at a predetermined current for a known period of time, the cathode plate on which deposition occurred was carefully removed and washed carefully in distilled water to remove any adhered suspension. The green deposit was slowly dried in air, followed by heating in an airoven at $\sim 120^{\circ} \mathrm{C}$ for complete drying. The weight of the deposit was measured by weighing the plates before and after the deposition. The deposited plates were then fired in an electrically heated furnace at $800-850^{\circ} \mathrm{C}$ to achieve adhesive glassceramic coating. Subsequently, the coatings were examined visually for surface quality, using an optical stereo microscope (Wild M 8Z stereo microscope); and coat thickness was measured by Micronstat FD/ND-coatingthickness gauge with (FD/ND) G-22-type probe.

\section{Results and discussion}

\subsection{Metal substrate preparation}

Pre-treatment process of metal substrate usually does not interfere in the process of electrophoretic deposition. This is carried out as required for conventional vitreous enamelling processes (Maskall and White 1986). However for mild steel substrate, galvanic corrosion occurs during the process and increases ionic conductance of the bath making it unsuitable for electrophoretic deposition. Phosphoric acid etching passivated the metal surface with the formation of ferric phosphate that prevents dissolution of free iron in the bath.

\subsection{Preparation of aqueous electrophoretic bath}

The choice of water as the suspension medium was justified because of its low cost, high dielectric constant, low viscosity, low volatility, and low conductance in pure form.

However, due to leaching of alkali ions from the powdered coating material in suspension, the specific conductance increases that results in a change in $\mathrm{pH}$ value of the bath which changes the zeta potential of the suspended particles. In case of a suspension of $16.0 \mathrm{CMC}, \mathrm{pH}$ changes from $7 \cdot 0$ to $9 \cdot 5$ that adversely affects the deposition efficiency and quality of the coating due to an increase in electrolysis. The zeta potentials of the glassceramic coating material particles change from $\sim-75.0 \mathrm{mV}$ to $\sim-100.0 \mathrm{mV}$ as $\mathrm{pH}$ changes from $7 \cdot 0$ to $9 \cdot 5$. The zeta potential of the particles in an aqueous bath is more in the acidic region $(\sim-150 \mathrm{mV}$ in the $\mathrm{pH}$ range $5 \cdot 0-6 \cdot 0)$. This unexpected change in zeta potential of the coating material particles may be due to leaching of alkali ions from the surface, particularly in an acidic bath. Electrophoretic deposition of the glass-ceramic coating material from the acidic aqueous bath is highly difficult. The alkali metal ions leach out into the surrounding acidic medium, and consequently an increase in electrolysis occurs. The process of electrolysis can however be avoided by using nonaqueous bath compositions like mixture of tri-chloro ethylene and $n$-butanol, acetone, ethanol and some other solvents.

The stability of the aqueous suspension showed its dependence on polymer concentration used in the bath. A mixture of $1.5: 8.0$ parts of polymer and coating material gave the most stable suspension with longest settling time and slowest settling rate. The uniformity in the thickness of deposition and covering of sharp edges of the substrate by the coating material has been found to be independent of experimental parameters. The surface finish of the resulting coating after firing depends on $\mathrm{pH}$ of the bath composition. The results have shown that at $\mathrm{pH} \sim 7.0$ the bath gives a coating of best surface finish with thickness uniformity of $\pm 5 \cdot 0 \mu$ in $50 \cdot 0$ to $100 \cdot 0 \mu$ total coat thickness. Hence, the process is expected to find good potentiality for coating various industrial and engineering components with suitable glass-ceramic coating by EPD from aqueous bath.

\subsection{Studies on EPD of glass-ceramic coating material}

The results of studies on the rate of deposition of coating materials (wt of deposit $/ \mathrm{cm}^{2} / \mathrm{min}$ ) at constant current and time, as shown in table 1 , indicates that it depends on the CMC present in the suspension i.e. it varies linearly within the experimental limit.

Figure 1 shows the variation of weight of deposition with time; and figure 2 shows the variation of rate of

Table 1. Change in rate of deposition with coating material concentration.

\begin{tabular}{lcc}
\hline Experiment no. & $\begin{array}{c}\mathrm{CMC} \\
(\mathrm{g} / 100 \mathrm{ml})\end{array}$ & $\begin{array}{c}\text { Rate of deposition with } \\
100 \mathrm{~mA} \text { current } \\
\left(\mathrm{mg} \mathrm{cm}^{-2} \cdot \mathrm{min}^{-1}\right)\end{array}$ \\
\hline 1 & $1 \cdot 0$ & $0 \cdot 71$ \\
2 & $3 \cdot 0$ & 0.90 \\
3 & $5 \cdot 0$ & $1 \cdot 343$ \\
\hline
\end{tabular}


deposition with applied voltage keeping other parameters constant. In both the cases, amounts of deposition increased linearly and continuously.

\subsection{Application of design of experiment}

The rate at which a deposit forms during EPD is critical, if the thickness of the deposited layer is to be controlled (Sarkar et al 1992). Hamaker (1940) proposed that the deposited weight is proportional to the concentration of the suspension, time of deposition, surface area of the deposit, and electric field: the proportionality constant being equal to the electrophoretic mobility of the suspended particles, assuming that every particle which reached the electrode gets deposited. Electrophoretic mobility of particles $(\mu)$ can be expressed as (Parfit 1973):

$$
\mu=\frac{Z E V}{4 \pi L \eta},
$$

where $Z$ is zeta potential, $E$ the dielectric constant of the suspending medium, $\eta$ the viscosity of the suspension, $L$ the electrode separation, and $V$ the applied voltage.

In case of a particular glass-ceramic coating material in an aqueous bath, with a fixed polymer concentration and $\mathrm{pH} ; Z, E$, and $\eta$ are kept constant; while $L$ is kept constant using the same electrode set up in all the experiments. The kinetics of EPD showed clearly that in case of a constant current and concentration deposition, weight of deposition indeed varied linearly with time; and in case of constant voltage and concentration deposition, the deposit resistivity increased with thickness, while the voltage drop/unit

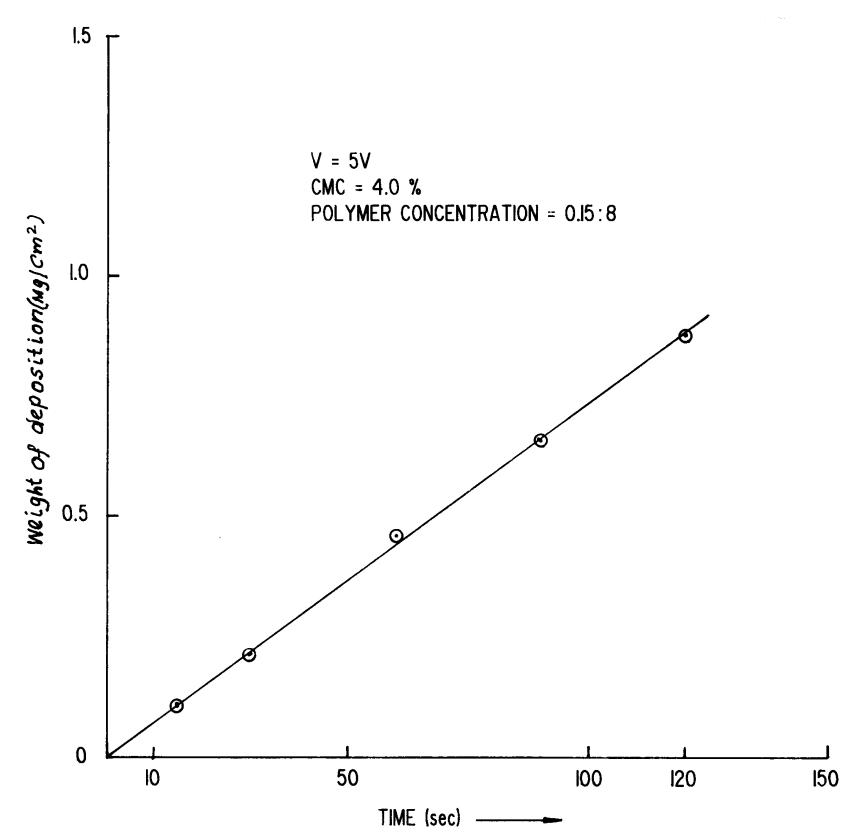

Figure 1. Variation of weight of deposition with time. length of suspension decreased with time (Sarkar and Nicholson 1996; Sarkar et al 1997b). As a result, deposition rate showed a decrease. Hence, constant current deposition is selected as the more suitable process to study. Thus, to evolve a meaningful regression equation for EPD of glass-ceramic coating materials from an aqueous bath, coating material concentration (CMC), applied current and time have been selected and studied over a pre-determined range.

Experimental values of rate of deposition of glassceramic coating materials have been expressed as weight of deposition per unit substrate area per unit time (response Y; weight of deposit in $\mathrm{mg} / \mathrm{cm}^{2} / \mathrm{min}$ ) for different combinations of independent experimental variables, coating material concentration in the bath, time of deposition and applied current keeping other parameters (temperature, polymer concentration, etc) constant. In the framework of factorial design of experiment (Kafarov 1976), $X_{\mathrm{i}}$, which stands for the coded value that corresponds to the natural value $Z_{\mathrm{i}}$ of the $\mathrm{i}$-th independent variable, can be expressed as:

$$
X_{\mathrm{i}}=\frac{Z_{\mathrm{i}}-Z_{\mathrm{i}}^{0}}{\left(Z_{\mathrm{i}}^{\mathrm{u}}-Z_{\mathrm{i}}^{\mathrm{l}}\right)_{2}},
$$

where $Z_{\mathrm{i}}^{0}, Z_{\mathrm{i}}^{\mathrm{u}}$ and $Z_{\mathrm{i}}^{\mathrm{l}}$ are the base, upper- and lower-level values, respectively, of the $\mathrm{i}$-th factor. It is to be noted that by definition, the base level can therefore be expressed as:

$$
Z_{\mathrm{i}}^{0}=\frac{Z_{\mathrm{i}}^{\mathrm{u}}+Z_{\mathrm{i}}^{\mathrm{l}}}{2} .
$$

In the present investigation the lower- and upper-level values of the parameters are shown in table 2.

Since, there are three variable parameters, the total number of experiments conducted were $2^{3}=8$. The

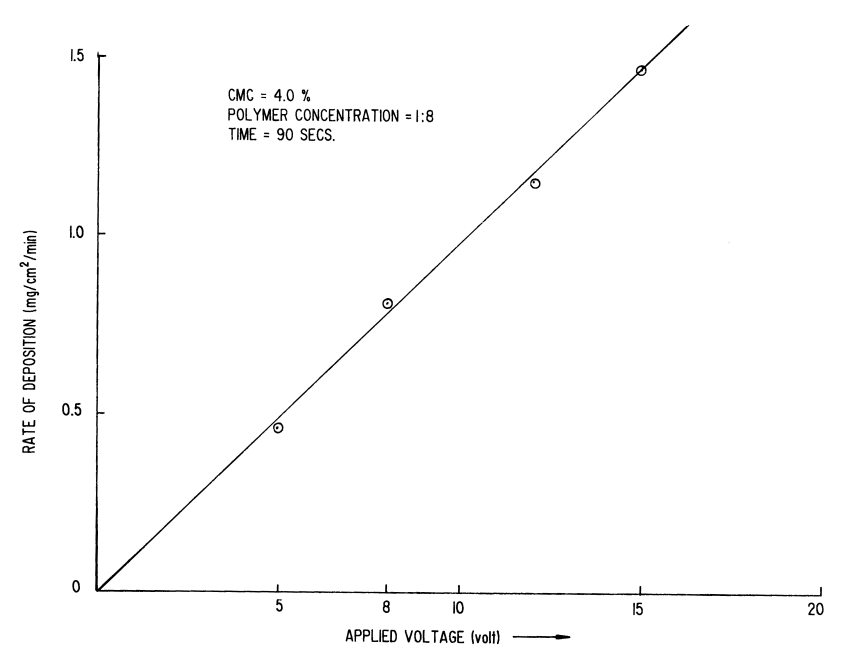

Figure 2. Variation of rate of deposition with voltage. 
experimental observations in coded-matrix form are given in table 3, where + and - denote higher and lower levels of the corresponding parameter.

Rate of deposition values of the glass-ceramic coating materials at the base level, corresponding to the experimental conditions, is reported in table 4.

To analyse the experimental data, a simple linear regression equation has been assumed. This is given by

$$
Y=b_{0}+b_{1} X_{1}+b_{2} X_{2}+b_{3} X_{3}
$$

By applying the method of least square to the data of table 3 , the coefficients $b_{\text {i }}$ were calculated and correspondingly substituted in the regression equation, giving

$$
Y=0 \cdot 9+0 \cdot 148 X_{1}+0 \cdot 355 X_{2}-0 \cdot 24 X_{3}
$$

To test whether the coefficients of (4) are significant or not, ' $t$ '-test was carried out. For this, first of all from the data given in table 4 , the average value of the rate of deposition at the base level was calculated, i.e.

$$
\bar{Y}_{0}=\frac{\sum_{i=1}^{3} Y_{\mathrm{i}}^{0}}{m}=0 \cdot 9,
$$

where ' $m$ ' is the number of replicates. Subsequently, table 5 was constructed to compute the error mean square, where $Y_{1}^{0}$ is the rate of deposition value in the $\mathrm{i}$-th replicate at the base level. Thus from table 5, the derived value of the error mean square, using the following given expression, was obtained, i.e.

Table 2. Lower- and upper-level values of the parameters.

\begin{tabular}{lcc}
\hline Parameter & Lower-level & Upper-level \\
\hline CMC (wt $\%)$ & $1 \cdot 0$ & $5 \cdot 0$ \\
Current (milli amperes) & 50 & 150 \\
Time (min) & 1 & 5 \\
\hline
\end{tabular}

Table 3. Experimental observations in coded-matrix form.

\begin{tabular}{lccc}
\hline \multicolumn{2}{l}{ Experimental parameters } & \\
\cline { 1 - 2 } CMC & Current & Time & \\
\cline { 1 - 2 } $\mathrm{X}_{1}$ & $\mathrm{X}_{2}$ & $\mathrm{X}_{3}$ & $\begin{array}{c}\text { Response (Y) rate of } \\
\text { deposition }\left(\mathrm{mg} / \mathrm{cm}^{2} / \mathrm{min}\right)\end{array}$ \\
\hline-1 & -1 & -1 & $0 \cdot 71$ \\
+1 & -1 & -1 & $0 \cdot 58$ \\
-1 & -1 & +1 & $0 \cdot 37$ \\
+1 & -1 & +1 & $0 \cdot 52$ \\
-1 & +1 & -1 & $1 \cdot 17$ \\
+1 & +1 & -1 & $2 \cdot 11$ \\
-1 & +1 & +1 & $0 \cdot 76$ \\
+1 & +1 & +1 & 0.99 \\
\hline
\end{tabular}

Note: + and - denote higher- and lower-levels of the corresponding parameter.

$$
S_{\mathrm{e}}^{2}=\frac{\sum\left(Y_{\mathrm{i}}^{0}-\bar{Y}^{0}\right)^{2}}{m-1}=\frac{0 \cdot 02}{2}=0 \cdot 01,
$$

therefore, $S_{\mathrm{e}}=0 \cdot 1$.

The $S b_{\mathrm{j}}$ (standard deviation of coefficient $b_{\mathrm{j}}$ 's) value was thus obtained by incorporating the above-derived value of $S_{\mathrm{e}}$ in the following expression:

$$
S b_{\mathrm{j}}=\frac{S_{\mathrm{e}}}{N^{1 / 2}}=\frac{0 \cdot 1}{8^{1 / 2}}=0 \cdot 0353553 .
$$

However, at a significant level of $p=0 \cdot 05$, and degree of freedom $f=m-1=2$, the tabulated value of the student ' $t$ '-distribution is obtainable, using the standard statistical table, i.e.

$$
t_{0.05}(2)=4 \cdot 303 \text {. }
$$

Thus computed values of $t_{\mathrm{j}}$ 's $\left(t_{0}=25 \cdot 456, t_{1}=4 \cdot 18\right.$, $t_{2}=10.04$ and $\left.t_{3}=6.788\right)$ were found to be more than or comparable with $t_{0.05}(2)$, and all the coefficients of (4) were also found to be significant.

To test the adequacy of (4), Fischer's-F-analysis was carried out. From table 2 and (4), table 6 was constructed: the $Y_{\mathrm{i}}$, and $\hat{Y}_{\mathrm{i}}$ respectively representing the experimentally observed rate of deposition and estimated rate of deposition values obtained from (4) in the i-th experiment. Now $S_{\mathrm{r}}^{2}$, the residual mean square can be defined as:

$$
S_{\mathrm{r}}^{2}=\frac{\sum\left(\hat{Y}_{\mathrm{i}}-Y_{\mathrm{i}}\right)^{2}}{N-1},
$$

where 1 is the number of significant coefficients in the regression equation as obtained from the ' $t$ '-test. For this

Table 4. Experimental observations at the base level.

\begin{tabular}{lc}
\hline $\begin{array}{l}\text { Number of } \\
\text { replicates }\end{array}$ & $\begin{array}{c}\text { Rate of deposition } \\
\left(\mathrm{mg} / \mathrm{cm}^{2} / \mathrm{min}\right)\end{array}$ \\
\hline 1 & $1 \cdot 0$ \\
2 & 0.9 \\
3 & 0.8 \\
\hline
\end{tabular}

$\mathrm{CMC}=3.0 \mathrm{wt} \%$, current $=100 \mathrm{~mA}$, time $=3 \mathrm{~min}$.

Table 5. Calculation of error mean square.

\begin{tabular}{lcc}
\hline Replicate & $Y_{\mathrm{i}}^{0}-\bar{Y}_{0}$ & $\left(Y_{\mathrm{i}}^{0}-\bar{Y}_{0}\right)^{2}$ \\
\hline 1 & $0 \cdot 1$ & $0 \cdot 01$ \\
2 & $0 \cdot 0$ & $0 \cdot 00$ \\
3 & $0 \cdot 1$ & $0 \cdot 01$ \\
\hline & \multicolumn{2}{c}{$\sum_{\mathrm{i}=1}^{3}\left(Y_{\mathrm{i}}^{0}-\bar{Y}_{0}\right)^{2}=0 \cdot 02$}
\end{tabular}


Table 6. Calculation of residual mean square.

\begin{tabular}{lcccc}
\hline $\begin{array}{l}\text { Experiment } \\
\text { number, } \mathrm{i}\end{array}$ & $Y_{\mathrm{i}}$ & $\hat{Y}_{\mathrm{i}}$ & $\left(\hat{Y}_{\mathrm{i}}-Y_{\mathrm{i}}\right)$ & $\left(\hat{Y}_{\mathrm{i}}-Y_{\mathrm{i}}\right)^{2}$ \\
\hline 1 & 0.71 & 0.637 & 0.073 & 0.005 \\
2 & 0.58 & 0.933 & 0.353 & 0.125 \\
3 & 0.37 & 0.157 & 0.213 & 0.045 \\
4 & 0.52 & 0.453 & 0.067 & 0.004 \\
5 & 1.17 & 1.347 & 0.177 & 0.031 \\
6 & 2.11 & 1.643 & 0.467 & 0.218 \\
7 & 0.76 & 0.867 & 0.107 & 0.011 \\
8 & 0.99 & 1.163 & 0.173 & 0.03 \\
\hline & & & \multicolumn{3}{c}{$\sum_{\mathrm{i}=1}\left(\hat{Y}_{\mathrm{i}}-Y_{\mathrm{i}}\right)^{2}=0.469$}
\end{tabular}

particular case, where $N=8$ and $1=4$, and based on the data from table 6 , we get the value of $S_{\mathrm{r}}^{2}$, i.e.

$$
S_{\mathrm{r}}^{2}=\frac{0 \cdot 47}{4}=0 \cdot 1175
$$

Thus variance ratio, $F$ is given by

$$
F=\frac{S_{\mathrm{r}}^{2}}{S_{\mathrm{e}}^{2}}=\frac{0 \cdot 1175}{0 \cdot 01}=11 \cdot 75,
$$

for $f_{1}=N-1=4$ and $f_{2}=m-1=2$, and at a significance level of $p=0.05$; the value of Fischer's $F$ from standard statistical table is, $F_{0.05}(4,2)=19 \cdot 2$. Since computed $F$, based on (4) is smaller than $F_{0.05}(4,2)$, it can be inferred that (4) is adequate.

Although, the linear regression equation (4) is adequate, it is logical to study the effects of the binary interaction terms, for example, $X_{1} X_{2}, X_{1} X_{3}, X_{2} X_{3}$ and $X_{1} X_{2} X_{3}$, in the regression equation. Then on the basis of data from table 3 and using least square method, the best nonlinear regression equation will be given by

$$
\begin{aligned}
Y= & 0 \cdot 9+0 \cdot 148 X_{1}+0 \cdot 355 X_{2}-0 \cdot 24 X_{3}+0 \cdot 142 X_{1} X_{2} \\
& -0 \cdot 052 X_{1} X_{3}-0 \cdot 14 X_{2} X_{3}-0 \cdot 122 X_{1} X_{2} X_{3} .
\end{aligned}
$$

The $t$-test was carried out using the procedure as detailed earlier for the linear equation (4). It was found that all the calculated $t_{\mathrm{j}}$ 's for the interaction terms $\left(t_{\mathrm{j} 2}=4.03\right.$, $t_{13}=1.49, t_{23}=3.96$ and $t_{123}=3.46$ ) from (6) were less than the tabulated $t_{0.05}(2)$. So none of the interaction terms were really significant.

This means that (4) can predict rate of deposition of glass-ceramic coating materials for parameters changed within the specified range. For example, the computed value, $0.9 \mathrm{mg} / \mathrm{cm}^{2} / \mathrm{min}$, of rate of deposition at the base level was in very good agreement with the experimentally observed average rate of deposition value of 0.9 (table 4).

\section{Conclusion}

The regression equation is found to be very satisfactory, and is in tune with the experimental results. The rate of electrophoretic deposition of glass-ceramic coating materials from aqueous bath is dependent on total number of particles present in the bath, current passing through the electrodes, and with time. However, with increasing time of deposition, the cathode (depositing electrode) is shielded more and more by deposit layer which results in an effective voltage drop that retards the process of further deposition. This was indeed reflected in the regression equation as well.

\section{Acknowledgement}

The author wishes to express his deep gratitude to Dr G C Das, Metallurgical Engineering Department, Jadavpur University, Calcutta, for his valuable suggestions regarding design of experiments.

\section{References}

Biswas K K, Datta S, Das S K, Ghose M C, Mazumder A and Ray N 1986 Trans. Indian Ceram. Soc. 4543

Das R K, Ray H S and Chander S 1979 Trans. Indian Inst. Metals 32364

Datta Someswar 1995 Handbook of ceramics (ed.) S Kumar (Calcutta: Kumar \& Associates) Vol. II chap. 12

Datta Someswar 1998 Bull. Mater. Sci. 21421

Hamaker H C 1940 Trans. Faraday Soc. 36279

Hoffman H and Rickmann B 1978 Am. Ceram. Soc. Bull. 57 605

Kafarov Y 1976 Cybernatic methods in chemistry and chemical engineering (Moscow: Mir Publishers)

Maiti H S, Basu R N and Datta S 1989 Phase Trans. 19139

Maskall K A and White D 1986 Vitreous enamelling: A guide to modern enamelling practice (London: Institute of Ceramics, Pergamon Press)

Nicholson P S, Sarkar P and Datta S 1996 Am. Ceram. Soc. Bull. 7548

Parfit G D 1973 Dispersion of powders in liquids (London: Appl. Sc. Publishers Ltd.)

Ramasamy A, Totlani M K and Ramanathan P S 1983 J. Electrochem. Soc. (India) 32113

Sarkar Partho and Nicholson Patrick S 1996 J. Am. Ceram. Soc. 791987

Sarkar P, Huang X and Nicholson P S 1992 J. Am. Ceram. Soc. 752907

Sarkar P, Datta S and Nicholson P S 1997a Composites Part-B B28 49

Sarkar Partho, Datta Someswar and Nicholson Patrick S 1997b Innovative processing and synthesis of ceramics, glasses, and composites (eds) N P Bansal, K V Logan and J P Singh (The American Ceramic Society) 85 p 231

Sen R, Datta S, Das S K and Basu S K 1989 Wear 130249

Sinha Mahapatra A K and Dhananjayan N 1981 Trans. Indian Inst. Metals 34495 